\title{
Social interaction attenuates the extent of secondary neuronal damage following closed head injury in mice
}

\author{
Vanessa M. Doulames ${ }^{1,2}$, Meghan Vilcans ${ }^{1,3}$, Sangmook Lee ${ }^{1,3}$ and Thomas B. Shea ${ }^{1,2,3 *}$ \\ ${ }^{1}$ Center for Neurobiology and Neurodegeneration Research, UMass Lowell, Lowell, MA, USA, ${ }^{2}$ Biomedical and \\ Biotechnology Program, University of Massachusetts Lowell, Lowell, MA, USA, ${ }^{3}$ Department of Biological Sciences, \\ University of Massachusetts Lowell, Lowell, MA, USA
}

\section{OPEN ACCESS}

Edited by:

James P. Herman,

University of Cincinnati, USA

Reviewed by:

Nathan Evanson,

Cincinnati Children's Hospital Medical

Center, USA

Lawrence Reagan,

University of South Carolina, USA

${ }^{*}$ Correspondence:

Thomas B. Shea

Thomas_shea@uml.edu

Received: 15 April 2015 Accepted: 28 September 2015

Published: 15 October 2015

Citation:

Doulames VM, Vilcans M, Lee S and Shea TB (2015) Social interaction attenuates the extent of secondary neuronal damage following closed head injury in mice.

Front. Behav. Neurosci. 9:275

doi: 10.3389/fnbeh.2015.00275
Recovery following Traumatic Brain Injury (TBI) can vary tremendously among individuals. Lifestyle following injury, including differential social interactions, may modulate the extent of secondary injury following TBI. To examine this possibility under controlled conditions, closed head injury (CHI) was induced in C57Bl6 mice using a standardized weight drop device after which mice were either housed in isolation or with their original cagemates ("socially-housed") for 4 weeks. $\mathrm{CHI}$ transiently impaired novel object recognition (NOR) in both isolated and social mice, confirming physical and functional injury. By contrast, $Y$ maze navigation was impaired in isolated but not social mice at 1-4 weeks post $\mathrm{CHI}$. $\mathrm{CHI}$ increased excitotoxic signaling in hippocampal slices from all mice, which was transiently exacerbated by isolation at 2 weeks post $\mathrm{CHI}$. $\mathrm{CHI}$ slightly increased reactive oxygen species and did not alter levels of amyloid beta (Abeta), total or phosphotau, total or phosphorylated neurofilaments. $\mathrm{CHI}$ increased serum corticosterone in both groups, which was exacerbated by isolation. These findings support the hypothesis that socialization may attenuate secondary damage following TBI. In addition, a dominance hierarchy was noted among socially-housed mice, in which the most submissive mouse displayed indices of stress in the above analyses that were statistically identical to those observed for isolated mice. This latter finding underscores that the nature and extent of social interaction may need to vary among individuals to provide therapeutic benefit.

Keywords: Traumatic Brain Injury, neurodegeneration, cognitive impairment, oxidative damage, socialization, secondary injury

\section{INTRODUCTION}

Traumatic Brain Injury (TBI) affects over 2 million Americans each year, resulting in $>\$ 70$ billion in direct and indirect expenditures since 2000 . The majority $(>75 \%)$ of instances of TBI are classified as closed head injuries (CHI; Corso et al., 2006; Finkelstein et al., 2006; Faul et al., 2010).

TBI encompasses primary and secondary injury. Primary injury encompasses structural damage characterized by the stretching, compression, and tearing of blood vessels and tissue, the extent of which is dependent upon the nature of impact (Maas et al., 2008). Integrity of the white-matter tracts is compromised via shearing forces resulting in both axonal and myelin damage; the extent of this white-matter damage has been correlated with reduced cognitive function (Niogi et al., 2008). 
Focal contusions create swelling and bleeding within brain tissue and can lead to behavioral and psychological changes due to scarring (Maas et al., 2008). Compromised membrane and ion channel integrity is often reported (Maas et al., 2008). Secondary injury encompasses an often protracted cascade of biochemical processes that are instigated by primary injury, resulting in excitotoxicity, cellular energy deficits, inflammation, oxidative stress, and apoptosis (Xiong et al., 1997; Raghupathi et al., 2000; Yi and Hazell, 2006; Ansari et al., 2008; Cederberg and Siesjö, 2010). Secondary injury can accumulate over time and may not be detected for days to years following the primary injury (Gavett et al., 2010; Gilbert and Johnson, 2011). In many cases, such as military combat and concussions accompanying contact sports, primary injury may be mild enough not to warrant the hospitalization and medical care. In such instances, secondary injury can progress unchecked, often leading to neurodegeneration and cognitive dysfunction (Gavett et al., 2010; Borgens and Liu-Snyder, 2012; Glushakova et al., 2014).

Recovery following TBI varies tremendously. Many individuals do not improve following treatment but continue to decline due to secondary injury (Narayan et al., 2002). Secondary injury can progress unchecked in "mild" TBI (when there is no obvious initiating incident to warrant intervention). As such, secondary damage associated with mTBI can exceed that of more severe TBI. Timely intervention could potentially attenuate the degree of secondary injury.

Lifestyle may influence the consequences of secondary injury. A growing body of evidence supports the positive impact of socialization on other neurodegenerative conditions such as Alzheimer's disease (Shea and Rogers, 2014; Shea et al., 2014). Maintenance of a large social network delays cognitive decline (Ertel et al., 2008). Even one-on-one interaction with institutional caregivers maintained cognitive performance for nursing home residents (van der Ploeg et al., 2013). Social isolation has been implicated in impaired memory and cognitive performance in normal and transgenic mice, alterations in in turnover and biosynthesis of dopamine in aged rats, increased oxidative damage, hypercortisolism, and exacerbation of acute and chronic inflammatory processes (Sapolsky et al., 1997; Miura et al., 2002; Huong et al., 2005; Eluvathingal et al., 2006; Raison et al., 2006; Huang et al., 2011; Möller et al., 2011; Sapolsky, 2011; Doulames et al., 2014). Since aspects of the neurodegeneration accompanying secondary injury parallel neurodegneration in other conditions such as Alzheimer's and Parkinson's disease (Mortimer et al., 1985; Taylor et al., 1999; Lye and Shores, 2000; Goldman et al., 2006; Chen et al., 2007), it remains possible that social interaction may also attenuate, or facilitate recovery from, secondary injury following TBI. While there is to date no compelling evidence for efficacy of non-pharmacological approaches (Meyer et al., 2010; Bowen et al., 2011), there is neither any evidence of efficacy for more conventional approaches (e.g., physioand occupational therapy; Hellweg, 2012). Moreover, inclusion of social activity need not preclude any other therapeutic approaches. To test the hypothesis that social activity may curtail the extent of secondary damage following TBI, we examined the impact of housing of mice in groups or individually on cognitive function and biochemical parameters following experimentally-induced CHI. Our findings support the notion that social interaction may be beneficial as part of therapy following TBI.

\section{MATERIALS AND METHODS}

Normal C57B1/6J female mice, 9-12 months of age (30 in each of two experiments), obtained from Charles River, were housed in our facility for 7 days, after which they were subjected to $\mathrm{CHI}$ using a standardized weight drop device (Northeast Biomedical, Tyngsboro, MA) modeled according to Flierl et al. (2009). Briefly, mice were anesthetized with $3 \%$ isoflurane and oxygen at a rate of 0.5-1.0 liters per minute. The cranium was shaved, sterilized with povidone iodine followed by $70 \%$ ethanol and a $1 \mathrm{~cm}$ incision was made, exposing the coronal and sagittal sutures of the skull to allow reproducible location of $\mathrm{CHI}$ and to confirm lack of penetrating damage. The weighted rod of the device was aligned with upper left quadrant of the skull and allowed to free-fall from a height of $0.5 \mathrm{~cm}$. Following impact, the incision was closed via wound closure clips and the mouse was allowed to recover on a heated water-circulating pad until normal behavior resumed. Analgesic (0.015\% buprenorphine) was administered twice a day for 3 days following injury and weight, body condition, and behavior were monitored daily for up to 4 weeks. Following injury, half of these mice were housed socially with their original cage mates (2-3 mice per enclosure) or individually ( $n=15$ mice/housing condition in each of two experiments). An additional 10 mice housed socially (2 per cage) and not subjected to $\mathrm{CHI}$ were included to obtain baseline levels. Mice were observed daily.

Cognitive performance was quantified prior to (baseline), $24 \mathrm{~h}$ following $\mathrm{CHI}$, then weekly for 1 month following $\mathrm{CHI}$ by the Novel Object Recognition (NOR) and by navigation of a standard Y Maze as previously described (Antunes and Biala, 2012; Lee et al., 2012; Doulames et al., 2014). The Y Maze Spontaneous Alternation Test (Y Maze) is a reward-free behavioral test used to assess exploration of a novel environment by a mouse, with any sort of performance compromise being indicative of cognitive dysfunction. The Y Maze (TSE Systems; Chesterfield, MO, USA) consists of 3 identical gray PVC arms mounted symmetrically $\left(120^{\circ}\right.$ between arms) onto an equilateral triangular center compartment. Mice were gently placed in the center compartment of the maze and their movement was recorded for 5 min. Entry into an arm was defined by the mouse having all 4 feet within the arm. The pattern of exploration of the $\mathrm{Y}$ maze was analyzed over a $5 \mathrm{~min}$ interval. The frequency of visitation of the $3 \mathrm{arms}$ of the maze in sequence (e.g., left, right, bottom, left, right, bottom, etc.) vs. total arm changes regardless of sequence was defined as the "percent alternation". The total number of changes in arms over this 5 min interval was defined as an index of activity (Lee et al., 2012; Doulames et al., 2014). For NOR, each mouse was placed in a novel cage (arena) with 2 identical objects for 5 min (acclimation period), after which the mouse was removed, the arena cleaned (to remove any scent), one of the objects was replaced with a novel object, and the mouse was returned to the arena for an 
additional $5 \mathrm{~min}$ (test period). The amount of time the spent interacting with each object (e.g., touching, climbing, sniffing) was recorded. The test period was repeated $24 \mathrm{~h}$ later with the same original object but a different novel object. The above regimen (i.e., acclimation, followed by testing $5 \mathrm{~min}$ and $24 \mathrm{~h}$ after acclimation) was carried out at baseline, $24 \mathrm{~h}$ after $\mathrm{CHI}$, and at weekly intervals for 1 month after CHI. Values represent the $\%$ of time interacting with the novel object vs. the total time interacting with either object (time with novel object/(time with novel object + time with familiar object). The pattern of exploration of the Y maze was analyzed over a 5 min interval. The frequency of visitation of the 3 arms of the maze in sequence (e.g., left, right, bottom, left, right, bottom, etc.) vs. total arm changes regardless of sequence was defined as the "percent alternation". The total number of changes in arms over this 5 min interval was defined as an index of activity (Lee et al., 2012).

Housing, induction of $\mathrm{CHI}$ and cognitive testing were all carried out with the approval of our Institutional Animal Care and Use Committee. Following cognitive analyses, mice were sacrificed for biochemical, histological and electrophysiological analyses (also in accordance with our Institutional Animal Care and Use Committee) via $\mathrm{CO}_{2}$ asphyxiation and immediate decapitation; the same mice were used for all behavioral, biochemical and electrophysiological examination.

For monitoring of signaling, hippocampi were harvested and placed in oxygenated artificial cerebrospinal fluid $(0.125 \mathrm{mM}$ $\mathrm{NaCl}, 2.5 \mathrm{mM} \mathrm{KCl}, 0.1 \mathrm{mM} \mathrm{MgCl}_{2}, 0.2 \mathrm{mM} \mathrm{CaCl}_{2}, 0.125$ $\mathrm{mM} \mathrm{NaH}_{2} \mathrm{PO}_{4}, 25 \mathrm{mM} \mathrm{NaHCO}_{3}$ ) supplemented with $100 \mathrm{mM}$ sucrose (Serra et al., 2010). Sagittal slices $(750 \mu \mathrm{M})$ cut with a Stoelting tissue slicer under sterile conditions were bathed in oxygenated artificial cerebrospinal fluid and transferred to the electrode recording area within a petri dish containing a 60channel multielectrode array (MEA). Neuronal signaling was recorded over $30 \mathrm{~s}$ intervals using a DT9814 data acquisition system (Data Translation; Marlborough, MA, USA) and MEA1060-INV amplifier (Multichannel Systems). Signals $>4 \mathrm{mV}$ in amplitude were quantified across all channels as previously described by Zemianek et al. (2012, 2013a,b).

Corticosterone concentration was measured via the Corticosterone Enzyme Assay Kit (Arbor Assays, Ann Arbor, MI, USA) according to the manufacturer's instructions. Following sacrifice via $\mathrm{CO}_{2}$ asphyxiation, mice were exsanguinated via cardiac puncture. Blood was collected within the same $2 \mathrm{~h}$ period each morning to avoid potential variation due to circadian rhythm (e.g., Nelson et al., 1975). Blood samples were immediately allowed to clot on ice for $20 \mathrm{~min}$ prior to centrifugation $(2000 \times \mathrm{g}$ at $4^{\circ} \mathrm{C}$ for $\left.10 \mathrm{~min}\right)$. Aliquots $(10 \mu \mathrm{l})$ of the resulting serum supernatant were immediately diluted 1:200 with the kit Assay buffer and incubated with a corticosterone-peroxidase conjugate, a corticosterone anti-sheep polyclonal antibody, and visualized by incubation with horseradish peroxidase at $450 \mathrm{~nm}$.

Whole brains were homogenized with 20 strokes of a glass homogenizer and resuspended at $100 \mathrm{mg} / \mathrm{mL}$ in icecold phosphate-buffered saline (PBS; $\mathrm{pH} 7.4$ ) containing $0.05 \%$ butylated hydroxytoluene as an antioxidant. Homogenates were derived from 3 mice for each condition, and each homogenate was assayed in duplicate. Homogenates were clarified by centrifugation $\left(10,000 \mathrm{~g}\right.$ at $4^{\circ} \mathrm{C}$ for $\left.5 \mathrm{~min}\right)$ and the supernatants were frozen at $-80^{\circ} \mathrm{C}$ until analysis. Total antioxidant capacity was determined in brain tissue homogenates via the OxiSelect Total Antioxidant Capacity Assay (Cell BioLabs, San Diego, CA, USA) to determine total antioxidant action. Following the manufacturer's instructions, tissue was resuspended at 50 $\mathrm{mg} / \mathrm{mL}$ in PBS and centrifuged $\left(10,000 \times \mathrm{g}\right.$ at $4^{\circ} \mathrm{C}$ for $\left.10 \mathrm{~min}\right)$. Supernatants $(10 \mu \mathrm{g} / \mathrm{mL}$ total protein) were combined with an equal volume of a proprietary assay mixture containing $\mathrm{Cu}^{2+}$ and a reagent which reacted with $\mathrm{Cu}^{2+}$ that was reduced by the residual antioxidants in brain homogenates, and "mM copper reducing equivalents" were quantified spectrophotometrically at $492 \mathrm{~nm}$.

Aliquots of the above brain tissue homogenates were also analyzed by immunoblot analyses for amyloid beta (Abeta), phosphorylated and total tau and phosphorylated and total neurofilaments (Mortimer et al., 1985; Taylor et al., 1999; Meyer et al., 2010; Bowen et al., 2011). Homogenates were diluted to a final protein concentration of $5 \mathrm{mg} / \mathrm{ml}$ in $0.125 \mathrm{mM}$ Tris- $\mathrm{HCl}$ containing $1 \%$ Triton-X, $150 \mathrm{mM} \mathrm{NaCl}, 2 \mathrm{mM}$ EDTA/EGTA, and a protease/phosphatase inhibitor cocktail. Samples were centrifuged $\left(20 \mathrm{~min}\right.$ at $12000 \mathrm{rpm}$ at $\left.4^{\circ} \mathrm{C}\right)$ and the resulting supernatants diluted in $0.125 \mathrm{M}$ Tris- $\mathrm{HCl}$ containing 4\% SDS, 10\% 2-mercaptoethanol, 20\% glycerol, and $0.004 \%$ bromophenol blue, and boiled at $95^{\circ} \mathrm{C}$ for 5 min. Aliquots ( $40 \mu \mathrm{g}$ total protein) were electrophoresed, and the separated proteins transferred to nitrocellulose membrane and blocked for $1 \mathrm{~h}$ with 5\% non-fat milk in TBST (50 $\mathrm{mM}$ TrisHCl (pH 7.4) containing $150 \mathrm{mM} \mathrm{NaCl}$ and $0.1 \%$ Tween-20) at $4^{\circ} \mathrm{C}$ with shaking. Membranes were rinsed with TBST and incubated overnight at $4^{\circ} \mathrm{C}$ with 1:000 dilutions in TBST of PHF-1 (a mouse monoclonal directed against phosphorylated tau; Sigma Aldrich), Tau-5 (a mouse monoclonal antibody directed against tau regardless of phosphorylation state; LifeTechnologies), SMI-31 (a mouse monoclonal antibody directed against phosphorylated neurofilaments; Millipore) H31 (a rabbit polyclonal antibody generated in this laboratory against total neurofilaments regardless of phosphorylation state), DM1A (a mouse monoclonal antibody directed against $\alpha$-tubulin) and a 1:2000 dilution of AB5078P (a rabbit polyclonal antibody directed against the 1-42 isoform of Abeta Millipore, Billerica, MA, USA), followed by rinsing $3 \mathrm{X}$ with TBST, incubation for $1 \mathrm{~h}$ at room temperature with anti-mouse or anti-rabbit alkaline phosphatase-conjugated secondary antibodies, and visualization of immunoreactive species via BCIP/NBT. Immunoreactive species were quantified using Image $\mathrm{J}$ software. $\mathrm{AD}$ is accompanied by an increase in phosphorylation of tau is hyperphosphorylated at serine residues 396 and 404; resultant phospho-isoforms are specifically are recognized by monoclonal antibody PHF-1 (Otvos et al., 1994). We therefore derived a ratio of PHF-1-reactive tau vs. total tau (as visualized by antibody Tau-5, which reacts with tau regardless of phosphorylation state). Assay of antitubulin via antibody DM1A was utilized as a loading control. 
Statistical comparisons of samples from three homogenates were carried out by ANOVA with post hoc analyses via Student's $t$ tests.

\section{RESULTS}

NOR following CHI was analyzed via NOR test at $5 \mathrm{~min}$ and $24 \mathrm{~h}$ after acclimation (Figure 1A). After 3 weeks post CHI, all mice displayed a transient decline in NOR 5 min after acclimation (Figure 1A). Isolated mice displayed a significant decline $(p<0.01)$, while socially-housed mice displayed only a trend towards significant decline $(p<0.07)$; NOR by both groups returned to levels statistically identical with baseline by 4 weeks. Over the first 3 weeks post CHI, all mice also displayed a significant decline in NOR at $24 \mathrm{~h}$ after acclimation, with a degree of improvement by 4 weeks post CHI (Figure 1).

Socially-housed mice maintained performance in $\mathrm{Y}$ maze navigation identical to that at baseline for the entire 4 weeks following CHI. By contrast, mice housed under isolated conditions significantly declined in performance by 1 week following $\mathrm{CHI}$, and continued to display significantly impaired performance for the entire 4 weeks (Figure 1B). Isolated mice also displayed a significant $(p<0.05)$ decline in total activity at 3 and 4 weeks following $\mathrm{CHI}$; socially-housed mice maintained performance identical to that of baseline for the entire 4 weeks after CHI (Figure 1B).

A significant $(p<0.02)$ increase in high amplitude $(>4 \mathrm{mV})$ signals was observed in hippocampal slices at both 2 and 4 weeks following CHI vs. levels observed at baseline (Figure 2; $p<0.02$ ). In addition, slices from mice maintained in isolation for 2 weeks following CHI displayed a further transient increase in high-amplitude signals $(p<0.02)$ compared to values at 4 weeks after $\mathrm{CHI}$ and to those observed from slices from socially-housed mice at 2 and 4 weeks after $\mathrm{CHI}$ (Figure 2).

CHI induced a 10-20\% reduction, not statistically significant) in antioxidant capacity in homogenates of brains from sociallyhoused and isolated mice at both 2 and 4 weeks after $\mathrm{CHI}$ capacity, indicating a minor induction of increased oxidative species following CHI (Figure 3).

Brain tissue homogenates were analyzed for increases in Abeta and increases in total or phosphorylation of tau and neurofilaments as indices of neurodegeneration. No differences were detected following $\mathrm{CHI}$ for either socially-housed or isolated mice (Figure 4).

Significantly elevated levels of corticosterone were observed in serum in both socially-housed and isolated mice at 2 and 4 weeks after CHI vs. baseline levels $(p<0.02)$; a transient further significant increase was observed in isolated mice at 2 weeks after $\mathrm{CHI}$ vs. isolated mice at 4 weeks and socially-housed mice at both 2 and 4 weeks after CHI ( $p<0.02$; Figure 5A).

Corticosterone levels were influenced by social hierarchy $(p<0.02$; Figure 5B). Daily observation allowed behavioral characterization of socially-housed mice (which were housed in groups of 3) as dominant (displaying the most aggressive behavior including barbering, territory marking, biting, and mounting), submissive (evidenced by extensive self-barbering,
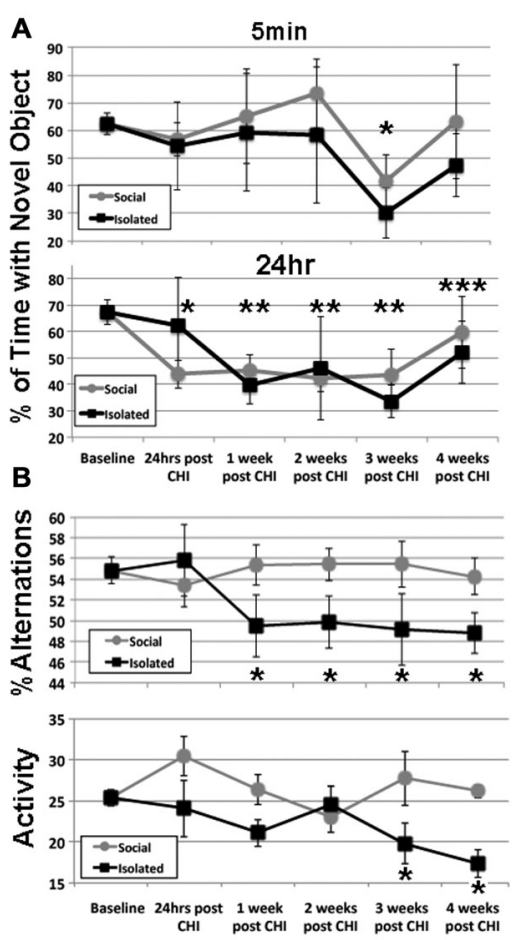

FIGURE 1 | Closed head injury (CHI) impaired cognitive performance; exacerbation by isolation. (A) Presents at $5 \mathrm{~min}$ and $24 \mathrm{~h}$ after acclimation as indicated. Values represent the mean ( \pm standard deviation) of the percentage of time devoted to the novel object (calculated according to the formula: seconds investigating novel object (seconds investigating novel object + seconds investigating familiar object). When tested 5 min after acclimation, both isolated and socially-housed mice displayed impaired performance at 3 weeks following $\mathrm{CHI}$ (asterisk; $p<0.07$ and 0.01 vs. baseline for socially-housed and isolated mice, respectively. Both groups displayed novel object recognition (NOR) that did not differ from baseline at 4 weeks after $\mathrm{CHI}$. When tested at $24 \mathrm{~h}$ after acclimation, socially-housed mice declined by $24 \mathrm{~h}$ after $\mathrm{CHI}$ ( $p<0.05$; single asterisk); isolated mice declined by an identical level by 1 week post $\mathrm{CH}$ and both groups continued to display significantly impaired NOR until 3 weeks post $\mathrm{CHI}$ ( $p<0.05$; double asterisks). At 4 weeks post $\mathrm{CHI}$, both social-housed and isolated mice displayed improvement in NOR $(p<0.07$ and $p=0.05$ vs. baseline, respectively; triple asterisks). (B) Presents the percent alteration and total activity as described in Materials and Methods. Socially-housed mice maintained performance in $Y$ maze navigation identical to that at baseline for the entire 4 weeks following $\mathrm{CHI}$. By contrast, mice housed under isolated conditions significantly declined in performance by 1 week following $\mathrm{CHI}$, and continued to display significantly impaired performance for the entire 4 weeks ( $p<0.05$; asterisks). Isolated mice also displayed a significant $(p<0.05)$ decline in activity at 3 and 4 weeks following $\mathrm{CHI}$ as quantified by total changes in arms of the $\mathrm{Y}$ maze $(p<0.05$; asterisks); socially-house mice maintained performance identical to that of baseline for the entire 4 weeks after $\mathrm{CHI}$.

being attacked and/or mounted and exclusion from a nest fashioned by the other 2 mice), and a third category which was submissive to the dominant mouse, yet dominant over the submissive mouse. These categories were defined as high-, lowand middle-rank, respectively. Among socially-housed mice, the highest corticosterone levels were observed in low-rank mice, the lowest corticosterone levels were observed in middle ranked mice, and levels between these two were observed in high ranked mice; these differences were significant. High- and low-rank 


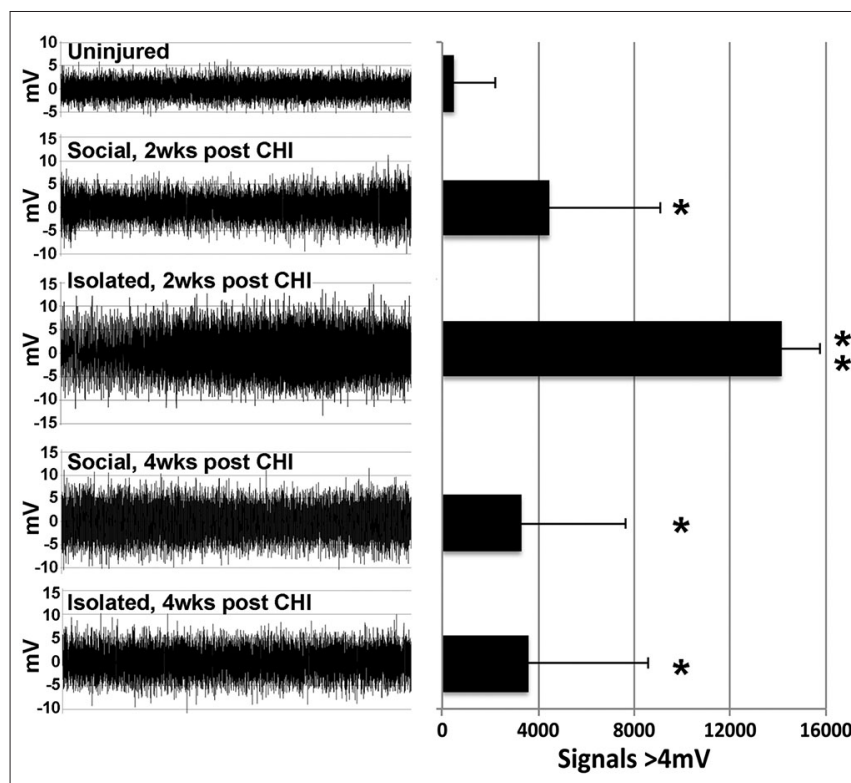

FIGURE 2 | $\mathrm{CHI}$ increased high amplitude signaling; isolation exacerbated this increase. Panels present representative $30 \mathrm{~s}$ recordings of synaptic signaling in hippocampal slice from mice prior to (Baseline) and at 2 and 4 weeks following $\mathrm{CHI}$. The accompanying graph presents quantification of signals $>4 \mathrm{mV}$ in amplitude. Values present the mean \pm standard deviation of total signals $>4 \mathrm{mV}$ in amplitude quantified from one slice from each of 4 mice per condition. $\mathrm{CH}$ significantly increased high amplitude signaling in all mice ( $p<0.02$; single asterisk). A transient further increase was noted for slices derived from isolated mice 2 weeks after $\mathrm{CHI}(p<0.02$ compared to all other conditions; double asterisk).

mice each displayed significantly elevated corticosterone levels at both 2 and 4 weeks following CHI vs. high- and low-rank mice not subjected to CHI (Figure 5B). Notably, the low-rank mice displayed corticosterone levels statistically identical to those of mice housed in isolation at 2 weeks post $\mathrm{CHI}$, and significantly greater than those of mice housed in isolation at 4 weeks post CHI (Figure 5B).

\section{DISCUSSION}

Essential towards development of and effective treatment for TBI is curtailing secondary injury. Secondary injury can be particularly insidious in that mild TBI can remain undetected, and/or be sufficiently benign that an individual fails to seek treatment. In such instances, unchecked secondary damage could equal or surpass that accompanying severe TBI for which therapeutic intervention was initiated. Herein, we utilized the reductionist approach of reproducible, experimental $\mathrm{CHI}$ in mice in efforts to determine whether or not social interaction could influence secondary injury. We considered that monitoring mice within $24 \mathrm{~h}$ after injury, followed by weekly observations for 1 month, would afford insight into whether any impact of $\mathrm{CHI}$ on cognitive or physiological parameters was derived exclusively from primary and/or secondary injury. Along this line of reasoning, observation of trauma within $24 \mathrm{~h}$ would indicate that it may have been derived from primary injury; by contrast, a more protracted appearance and/or increase in the

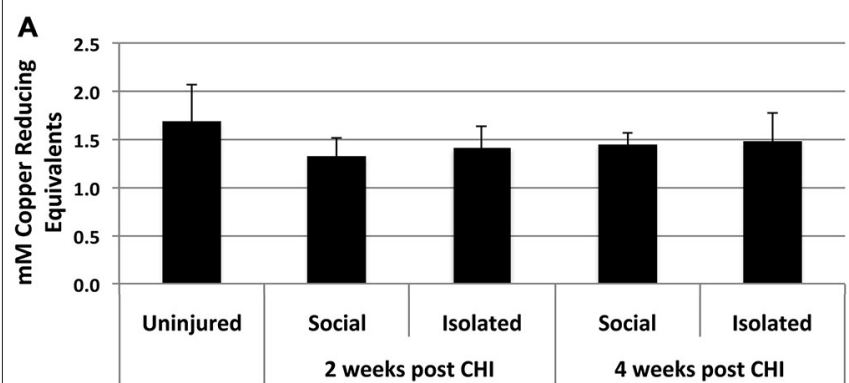

B

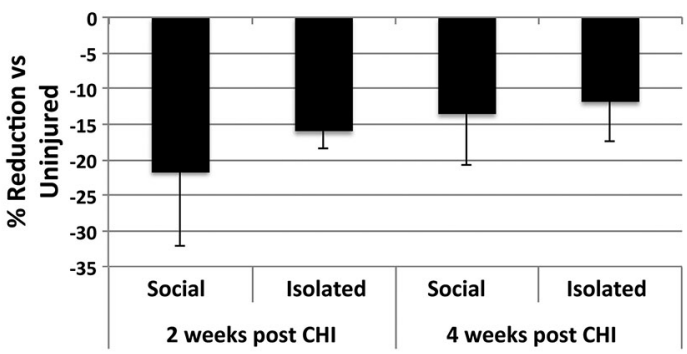

FIGURE 3 | CHI reduced total antioxidant capacity in brain tissue. (A) Presents the mean antioxidant capacity \pm standard deviation in $\mathrm{mM}$ copper reducing equivalents in for homogenates from brain tissue of uninjured mice and mice housed socially or individually for 2 and 4 weeks after $\mathrm{CHI}$ as indicated ( $n=3$ for each condition). (B) Presents the \% reduction ( \pm standard deviation) in antioxidant capacity for homogenates from brain tissue from mice subjected to $\mathrm{CHI}$ vs. uninjured mice. Mice subjected to $\mathrm{CHI}$ displayed decreases from 10-20\%; these decreases did not differ significantly from those of mice not subjected to $\mathrm{CHI}$ ( $p=0.26$; ANOVA).

extent of trauma over one or more weeks following CHI would be consistent with contribution (at least in part) of secondary injury. Our reductionist approach, which utilized differential housing of mice following CHI, allowed us to examine whether or not socialization could impact the nature and extent of injury. Our findings demonstrated that this was indeed the case: both cognitive and physiological facets of secondary injury were affected by differential housing. In our prior studies (Doulames et al., 2014), isolation for 4 weeks without CHI induced a decline in cognitive performance as assayed by $\mathrm{Y}$ maze navigation; however this decline was not significant vs. performance by mice maintained under social housing $(p=0.26)$. Herein, the decline in $\mathrm{Y}$ maze performance for mice maintained under isolation conditions for 4 weeks after $\mathrm{CHI}$ was significantly reduced compared to that of socially housed mice receiving $\mathrm{CHI}$ ( $p=0.02$; Student's $t$ test). These comparisons suggest that $\mathrm{CHI}$ impaired cognitive performance beyond that of isolation alone, and that housing under social conditions was capable of preventing the extent of decline induced by the combination of $\mathrm{CHI}$ followed by isolation. Notably, it remains unclear whether social interaction alleviated the progression of secondary injury, or instead whether isolation exacerbated secondary injury, or whether or not the differences observed between groups was derived in part by both.

Cognitive performance following CHI was affected by both primary and secondary injury, and furthermore was modulated by differential housing following CHI. CHI impaired both 


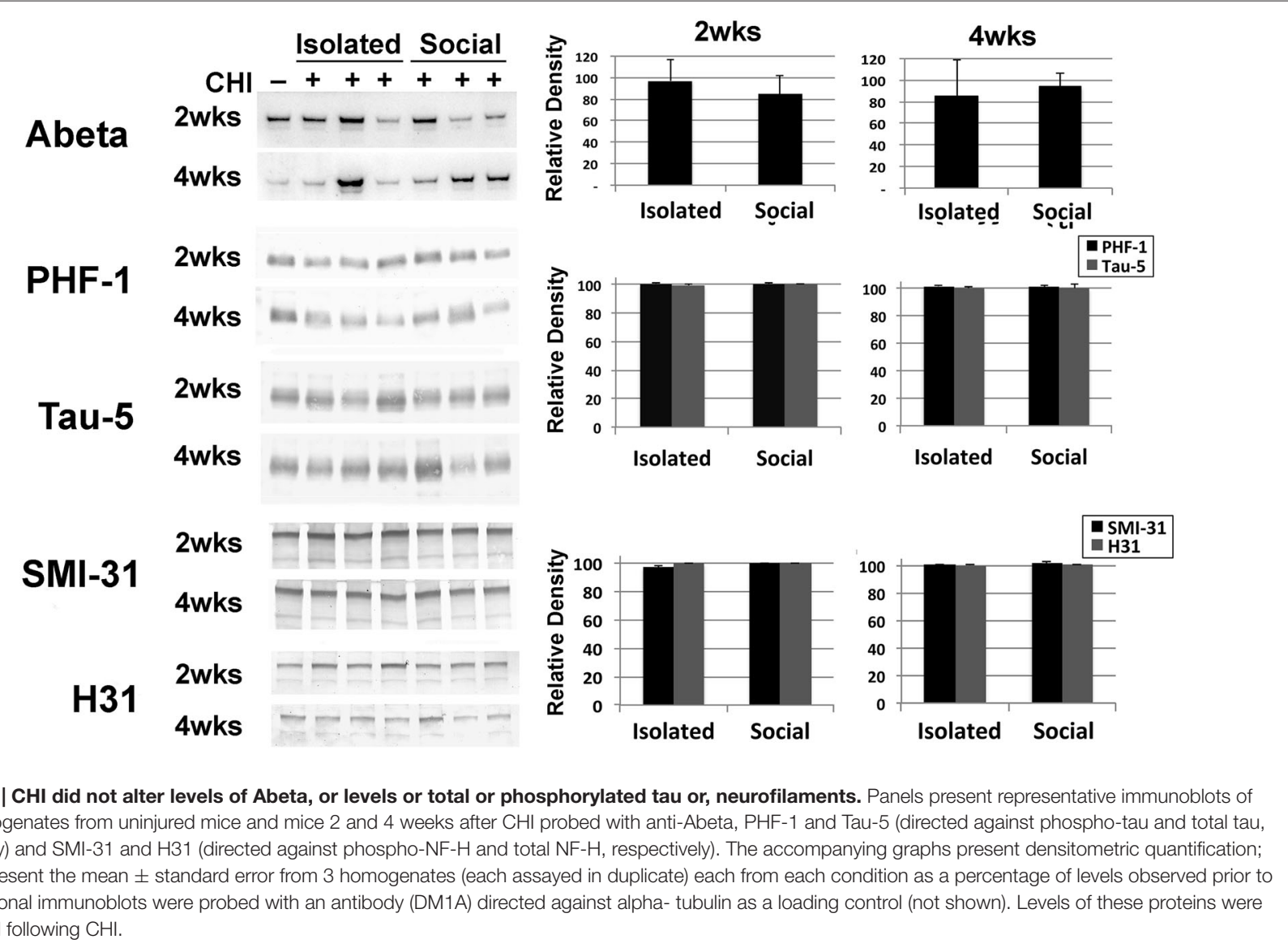

short- and long-term recognition memory as assayed by NOR at $5 \mathrm{~min}$ and $24 \mathrm{~h}$ after $\mathrm{CHI}$, respectfully. Short-term memory declined in mice transiently at 3 weeks after $\mathrm{CHI}$ for mice housed socially or in isolation, suggesting that this transient decline was due to secondary injury and was not affected by social interactions. Long-term memory following CHI displayed a more complex decline, in which socially-housed mice declined within $24 \mathrm{~h}$ but mice maintained in isolation instead declined 1 week following CHI. Of interest would have been to assay NOR at 36,48 and/or $72 \mathrm{~h}$ to determine more precisely the point at which isolated mice declined in long-term memory. Both groups continued to display impaired long-term memory until at least 3 weeks post $\mathrm{CHI}$, and had substantially recovered in NOR by the 4th week after $\mathrm{CHI}$, at which point their performance was nearly restored to that at baseline.

In contrast to NOR, Y maze navigation, which relies on spatial memory, was not impaired until 1 week following $\mathrm{CHI}$, and moreover, was only impaired in mice housed in isolation. This protracted decline, coupled with its observation only for mice housed in isolation, suggested that impairment in spatial memory was not due to primary injury. Moreover, prevention of this decline in socially-housed mice holds the promise that social interaction may be a useful part of a therapeutic approach to curtail secondary injury following TBI. Also in contrast to NOR, mice maintained in isolation did not recover in $\mathrm{Y}$ maze navigation. Of interest would be to monitor mice for longer intervals to determine whether or not there was a more protracted recovery. Nevertheless, the observation of recovery in NOR suggests that $\mathrm{CHI}$ utilized herein did not induce significant permanent loss of neuronal function. This is consistent with prior studies demonstrating memory impairment following mild TBI without substantial neuronal death (Yarnell and Lynch, 1970; Lyeth et al., 1990; Miyazaki et al., 1992; Cacioppo and Hawkley, 2009).

CHI significantly increased high amplitude signaling in hippocampal slices, which was transiently exacerbated by isolation at 2 weeks but not 4 weeks post CHI. This finding is consistent with the association of excitotoxicity with secondary injury following TBI (Palmer et al., 1993; Brown et al., 1998; Rao et al., 1998; Yi and Hazell, 2006), and may in part underlie impaired cognitive performance.

Consistent with prior studies with rodents (Awasthi et al., 1997; Tyurin et al., 2000; Ansari et al., 2008) and with clinical findings (Bayir et al., 2002), we observed a reduction in total antioxidant capacity following $\mathrm{CHI}$, indicative of increased oxidative stress. No differences in total antioxidant capacity were observed between socially-housed and isolated mice. Of interest would be to quantify reactive oxygen species and overall levels of oxidized protein and lipids. 


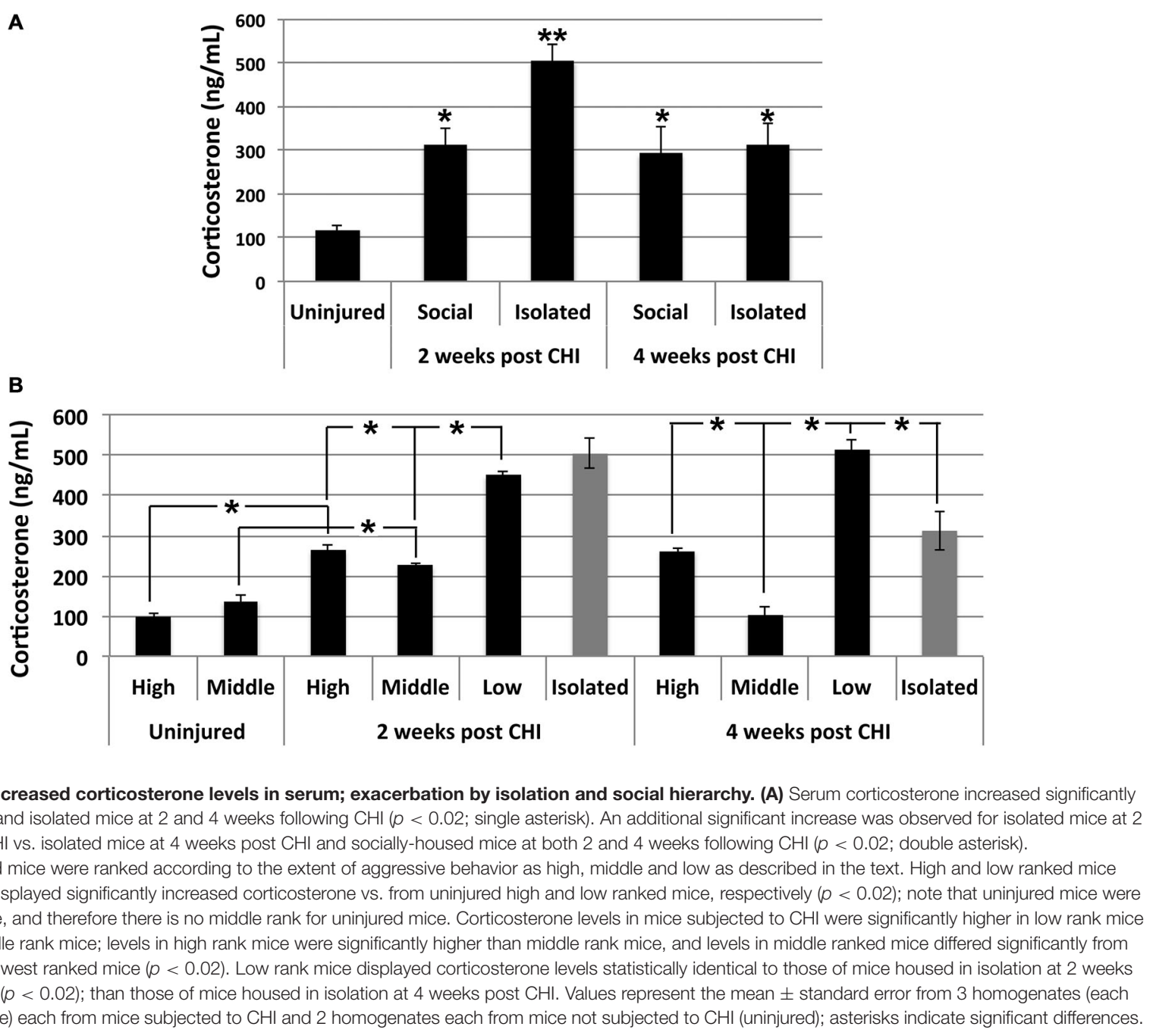

Corticosterone levels were monitored as an index of overall stress (Levine and Treiman, 1964; Goodman et al., 1996). CHI significantly increased corticosterone, and this increase was transiently exacerbated by isolation at 2 weeks post CHI. Social hierarchy also exacerbated corticosterone levels following CHI. High-rank mice within their respective groups of 3 displayed aggressive behavior including barbering, territory marking, biting, and mounting both middle-rank and lowrank mice. Middle-rank mice also displayed dominant behavior over low-rank mice. Consistent with prior studies (Louch and Higginbotham, 1967; Schuhr, 1987; Sapolsky, 1992, 2005, 2011; Sapolsky et al., 1997), corticosterone levels were observed in decreasing order as low-rank mice $>$ high-rank mice $>$ middlerank mice. Although observation of elevated corticosterone in high-rank vs. middle-rank mice may seem counterintuitive, high-rank mice undergo relatively more stress than middle-rank mice in order to maintain their dominance. Of interest was that low-rank mice displayed corticosterone levels identical to those of isolated mice at 2 weeks post $\mathrm{CHI}$, and significant higher than those of isolated mice by 4 weeks post CHI. Extrapolation of these findings to humans leaves open the possibility that the nature and extent of social interactions will likely differ among individuals; while social interaction may indeed form an important part of a therapeutic program following TBI, no single form of social interaction will be appropriate for all individuals. For example, group meetings may be appropriate for some individuals (Ertel et al., 2008), while, conversely, limiting interactions to relatively brief one-on-one conversations with a therapist may be more appropriate for others (van der Ploeg et al., 2013).

A limitation of our study is that we did not sacrifice mice immediately following $\mathrm{CHI}$ for monitoring of signaling or biochemical analyses, which would have allowed us to determine whether or not the increases in oxidative species, excitotoxic signaling and corticosterone accompanied primary injury or instead accumulated by week 2 post $\mathrm{CHI}$ as a consequence of secondary injury, or both. However, since excitotoxic signaling and corticosterone underwent transient exacerbation in isolated mice, it is likely that these deleterious effects were at the very least enhanced by secondary injury; had they been entirely 
due to primary injury, both groups of mice would have been equally affected. Of interest would be to group 2 or 3 of the low-rank or middle-rank mice together, to determine whether or not this would alleviate corticosterone elevation following $\mathrm{CHI}$, or whether a new dominance hierarchy would emerge. Similarly, grouping isolated mice after, e.g., 1 or 2 weeks may allow reversion of some of the impact of isolation following $\mathrm{CHI}$.

No changes levels of Abeta, or levels and/or phosphorylation of tau or neurofilaments were observed following $\mathrm{CHI}$ as administered herein. This finding is consistent with our observation of cognitive recovery, but contrasts with studies demonstrating that even a single mild TBI can fosters alterations in these neurodegenerative hallmarks (Smith et al., 1999; Schmidt et al., 2001; Franz et al., 2003; McKee et al., 2009; Gavett et al., 2010; Johnson et al., 2012). Monitoring mice for a longer interval, post $\mathrm{CHI}$, especially those maintained in isolation, may reveal protracted accumulation of Abeta or cytoskeletal abnormalities; however, other studies show can see increased phosphorylation of tau within $24 \mathrm{~h}$ and lasts up to 30 days (Huber et al., 2013). Methods for modeling TBI vary considerably; one possibility is therefore that $\mathrm{CHI}$ as administered herein was milder than that used in prior studies. A stronger CHI could be administered, but perhaps of more interest would be to administer repetitive $\mathrm{CHI}$ under the conditions utilized herein, to model repetitive injury that can accompany contact sports.

\section{REFERENCES}

Ansari, M. A., Roberts, K. N., and Scheff, S. W. (2008). Oxidative stress and modification of synaptic proteins in hippocampus after traumatic brain injury. Free Radic Biol. Med. 45, 443-452. doi: 10.1016/j.freeradbiomed.2008.04.038

Antunes, M., and Biala, G. (2012). The novel object recognition memory: neurobiology, test procedure and its modifications. Cogn. Process. 13, 93-110. doi: 10.1007/s10339-011-0430-Z

Awasthi, D., Church, D. F., Torbati, D., Carey, M. E., and Pryor, W. A. (1997). Oxidative stress following traumatic brain injury in rats. Surg. Neurol. 47, 575-581; discussion 581-582. doi: 10.1016/s0090-3019(96)00461-2

Bayir, H., Kagan, V. E., Tyurina, Y. Y., Tyurin, V., Ruppel, R. A., Adelson, P. D., et al. (2002). Assessment of antioxidant reserves and oxidative stress in cerebrospinal fluid after severe traumatic brain injury in infants and children. Pediatr. Res. 51, 571-578. doi: 10.1203/00006450-20020500000005

Borgens, R. B., and Liu-Snyder, P. (2012). Understanding secondary injury. Q. Rev. Biol. 87, 89-127. doi: 10.1086/665457

Bowen, A., Knapp, P., Gillespie, D., Nicolson, D. J., and Vail, A. (2011). Nonpharmacological interventions for perceptual disorders following stroke and other adult-acquired, non-progressive brain injury. Cochrane Database Syst. Rev. 13:CD007039. doi: 10.1002/14651858.cd007039

Brown, J. I., Baker, A. J., Konasiewicz, S. J., and Moulton, R. J. (1998). Clinical significance of CSF glutamate concentrations following severe traumatic brain injury in humans. J. Neurotrauma 15, 253-263. doi: 10.1089/neu.1998.15.253

Cacioppo, J. T., and Hawkley, L. C. (2009). Perceived social isolation and cognition. Trends Cogn. Sci. 13, 447-454. doi: 10.1016/j.tics.2009.06.005

Cederberg, D., and Siesjö, P. (2010). What has inflammation to do with traumatic brain injury? Childs Nerv. Syst. 26, 221-226. doi: 10.1007/s00381-009-1029-x

Chen, H., Richard, M., Sandler, D. P., Umbach, D. M., and Kamel, F. (2007). Head injury and amyotrophic lateral sclerosis. Am. J. Epidemiol. 166, 810-816. doi: 10.1093/aje/kwm153

Corso, P., Finkelstein, E., Miller, T., Fiebelkorn, I., and Zaloshnja, E. (2006). Incidence and lifetime costs of injuries in the united states. Inj. Prev. 12, 212-218. doi: 10.1136/ip.2005.010983
The various deleterious consequences observed herein following $\mathrm{CHI}$ are likely to be inter-related at least in part. For example, excessive corticosterone exposure can exacerbate excitotoxicity (Goodman et al., 1996), which may be reflected by our observation of high amplitude signals in hippocampal slices from mice 2 weeks post CHI. Hippocampal signaling abnormalities are anticipated to be reflected by impairment in memory. Chronic stress, reflected herein by increased corticosterone, impairs memory (Pavlides et al., 1993; McEwen, 1999). Oxidative stress both induces excitotoxicity and impairs memory (Daulatzai, 2013; Rachmany et al., 2013). These events likely occur in a deleterious feedback mechanism, since, for example, oxidative stress induces anxiety, which can further elevate corticosterone (Salim et al., 2011). Our demonstration that social isolation impairs cognitive performance, increases stress, and exacerbates excitotoxicity supports the notion that pro-active approaches including social interaction may influence the rate and extent of recovery following TBI.

Environmental enrichment has been shown to boost cognitive performance in mice not subjected to $\mathrm{CHI}$, using the same cognitive tests as utilized herein, including augmenting the impact of social interaction (Doulames et al., 2014). Of interest would be to examine whether or not environmental enrichment, with and without housing in groups vs. isolation, would be effective following $\mathrm{CHI}$.

Daulatzai, M. A. (2013). Neurotoxic saboteurs: straws that break the hippo's (hippocampus) back drive cognitive impairment and alzheimer's disease. Neurotox. Res. 24, 407-459. doi: 10.1007/s12640-013-9407-2

Doulames, V., Lee, S., and Shea, T. B. (2014). Environmental enrichment and social interaction improve cognitive function and decrease reactive oxidative species in normal adult mice. Int. J. Neurosci. 124, 369-376. doi: 10.3109/00207454. 2013.848441

Eluvathingal, T. J., Chugani, H. T., Behen, M. E., Juhász, C., Muzik, O., Maqbool, M., et al. (2006). Abnormal brain connectivity in children after early severe socioemotional deprivation: a diffusion tensor imaging study. Pediatrics 117, 2093-2100. doi: 10.1542/peds.2005-1727

Ertel, K. A., Glymour, M. M., and Berkman, L. F. (2008). Effects of social integration on preserving memory function in a nationally representative US elderly population. Am. J. Public Health 98, 1215-1220. doi: 10.2105/ajph.2007. 113654

Faul, M., Xu, L., Wald, M. M., and Coronado, V. G. (2010). Traumatic Brain Injury in the United States: Emergency Department Visits, Hospitalizations and Deaths 2002-2006. Atlanta, GA: Centers for Disease Control and Prevention, National Center for Injury Prevention and Control.

Finkelstein, E., Corso, P. S., and Miller, T. R. (2006). The Incidence and Economic Burden of Injuries in the United States. Oxford, NY: Oxford University Press.

Flierl, M. A., Stahel, P. F., Beauchamp, K. M., Morgan, S. J., Smith, W. R., and Shohami, E. (2009). Mouse closed head injury model induced by a weight-drop device. Nat. Protoc. 4, 1328-1337. doi: 10.1038/nprot.2009.148

Franz, G., Beer, R., Kampfl, A., Engelhardt, K., Schmutzhard, E., Ulmer, H., et al. (2003). Amyloid beta 1-42 and tau in cerebrospinal fluid after severe traumatic brain injury. Neurology 60, 1457-1461. doi: 10.1212/01.wnl.0000063313. 57292.00

Gavett, B. E., Stern, R. A., Cantu, R. C., Nowinski, C. J., and McKee, A. C. (2010). Mild traumatic brain injury: a risk factor for neurodegeneration. Alzheimers Res. Ther. 2:18. doi: 10.1186/alzrt42

Gilbert, F., and Johnson, L. S. M. (2011). The impact of american tackle footballrelated concussion in youth athletes. AJOB Neurosci. 2, 48-59. doi: 10. $1080 / 21507740.2011 .611125$ 
Glushakova, O. Y., Johnson, D., and Hayes, R. L. (2014). Delayed increases in microvascular pathology after experimental traumatic brain injury are associated with prolonged inflammation, blood-brain barrier disruption and progressive white matter damage. J. Neurotrauma 31, 1180-1193. doi: 10. 1089/neu.2013.3080

Goldman, S. M., Tanner, C. M., Oakes, D., Bhudhikanok, G. S., Gupta, A., and Langston, J. W. (2006). Head injury and parkinson's disease risk in twins. Ann. Neurol. 60, 65-72. doi: 10.1002/ana.20882

Goodman, Y., Bruce, A. J., Cheng, B., and Mattson, M. P. (1996). Estrogens attenuate and corticosterone exacerbates excitotoxicity, oxidative injury and amyloid beta-peptide toxicity in hippocampal neurons. J. Neurochem. 66, 1836-1844. doi: 10.1046/j.1471-4159.1996. 66051836.x

Hellweg, S. (2012). Effectiveness of physiotherapy and occupational therapy after traumatic brain injury in the intensive care unit. Crit. Care Res. Pract. 2012:768456. doi: 10.1155/2012/768456

Huang, H. J., Liang, K. C., Ke, H. C., Chang, Y. Y., and Hsieh-Li, H. M. (2011). Long-term social isolation exacerbates the impairment of spatial working memory in APP/PS1 transgenic mice. Brain Res. 1371, 150-160. doi: 10.1016/j. brainres.2010.11.043

Huber, B. R., Meabon, J. S., Martin, T. J., Mourad, P. D., Bennett, R., Kraemer, B. C., et al. (2013). Blast exposure causes early and persistent aberrant phosphoand cleaved-tau expression in a murine model of mild blast-induced traumatic brain injury. J. Alzheimers Dis. 37, 309-323. doi: 10.3233/JAD-130182

Huong, N. T., Murakami, Y., Tohda, M., Watanabe, H., and Matsumoto, K. (2005). Social isolation stress-induced oxidative damage in mouse brain and its modulation by majonoside-R2, a Vietnamese ginseng saponin. Biol. Pharm. Bull. 28, 1389-1393. doi: 10.1248/bpb.28.1389

Johnson, V. E., Stewart, W., and Smith, D. H. (2012). Widespread tau and amyloidbeta pathology many years after a single traumatic brain injury in humans. Brain Pathol. 22, 142-149. doi: 10.1111/j.1750-3639.2011.00513.x

Lee, S., Doulames, V., Donnelly, M., Levasseaur, J., and Shea, T. B. (2012). Environmental enrichment can prevent cognitive decline induced by dietary oxidative challenge. J. Alzheimers Dis. 28, 497-501. doi: 10.3233/JAD-2011111562

Levine, S., and Treiman, D. M. (1964). Differential plasma corticosterone response to stress in four inbred strains of mice. Endocrinology 75, 142-144. doi: 10. 1210/endo-75-1-142

Louch, C. D., and Higginbotham, M. (1967). The relation between social rank and plasma corticosterone levels in mice. Gen. Comp. Endocrinol. 8, 441-444. doi: 10.1016/s0016-6480(67)80006-6

Lye, T. C., and Shores, E. A. (2000). Traumatic brain injury as a risk factor for alzheimer's disease: a review. Neuropsychol. Rev. 10, 115-129. doi: 10. 1023/A:1009068804787

Lyeth, B. G., Jenkins, L. W., Hamm, R. J., Dixon, C. E., Phillips, L. L., Clifton, G. L., et al. (1990). Prolonged memory impairment in the absence of hippocampal cell death following traumatic brain injury in the rat. Brain Res. 526, 249-258. doi: 10.1016/0006-8993(90)91229-a

Maas, A. I., Stocchetti, N., and Bullock, R. (2008). Moderate and severe traumatic brain injury in adults. Lancet. Neurol. 7, 728-741. doi: 10.1016/s14744422(08)70164-9

McEwen, B. S. (1999). Stress and hippocampal plasticity. Annu. Rev. Neurosci. 22, 105-122. doi: 10.1146/annurev.neuro.22.1.105

McKee, A. C., Cantu, R. C., Nowinski, C. J., Hedley-Whyte, E. T., Gavett, B. E., Budson, A. E., et al. (2009). Chronic traumatic encephalopathy in athletes: progressive tauopathy after repetitive head injury. J. Neuropathol. Exp. Neurol. 68, 709-735. doi: 10.1097/nen.0b013e3181a9d503

Meyer, M. J., Megyesi, J., Meythaler, J., Murie-Fernandez, M., Aubut, J. A., Foley, N., et al. (2010). Acute management of acquired brain injury part I: an evidence-based review of non-pharmacological interventions. Brain Inj. 24, 694-705. doi: 10.3109/02699051003692118

Miura, H., Qiao, H., and Ohta, T. (2002). Influence of aging and social isolation on changes in brain monoamine turnover and biosynthesis of rats elicited by novelty stress. Synapse 46, 116-124. doi: 10.1002/syn.10133

Miyazaki, S., Katayama, Y., Lyeth, B. G., Jenkins, L. W., DeWitt, D. S., Goldberg, S. J., et al. (1992). Enduring suppression of hippocampal long-term potentiation following traumatic brain injury in rat. Brain Res. 585, 335-339. doi: 10. 1016/0006-8993(92)91232-4
Möller, M., Du Preez, J. L., Emsley, R., and Harvey, B. H. (2011). Isolation rearing-induced deficits in sensorimotor gating and social interaction in rats are related to cortico-striatal oxidative stress and reversed by sub-chronic clozapine administration. Eur. Neuropsychopharmacol. 21, 471-483. doi: 10. 1016/j.euroneuro.2010.09.006

Mortimer, J. A., French, L. R., Hutton, J. T., and Schuman, L. M. (1985). Head injury as a risk factor for alzheimer's disease. Neurology 35, 264-267. doi: 10. 1212/wnl.35.2.264

Narayan, R. K., Michel, M. E., Ansell, B., Baethmann, A., Biegon, A., Bracken, M. B., et al. (2002). Clinical trials in head injury. J. Neurotrauma 19, 503-557. doi: 10.1089/089771502753754037

Nelson, W., Scheving, L., and Halberg, F. (1975). Circadian rhythms in mice fed a single daily meal at different stages of lighting regimen. J. Nutr. 105, 171-184.

Niogi, S. N., Mukherjee, P., Ghajar, J., Johnson, C., Kolster, R. A., Sarkar, R., et al. (2008). Extent of microstructural white matter injury in postconcussive syndrome correlates with impaired cognitive reaction time: a $3 \mathrm{~T}$ diffusion tensor imaging study of mild traumatic brain injury. AJNR Am. J. Neuroradiol. 29, 967-973. doi: 10.3174/ajnr.a0970

Otvos, L., Jr., Feiner, L.,Lang, E., Szendrei, G. I., Goedert, M., and Lee, V. M. (1994). Monoclonal antibody PHF-1 recognizes tau protein phosphorylated at serine residues 396 and 404. J. Neurosci. Res. 39, 669-673. doi: 10.1002/jnr. 490390607

Palmer, A. M., Marion, D. W., Botscheller, M. L., Swedlow, P. E., Styren, S. D., and DeKosky, S. T. (1993). Traumatic brain injury-induced excitotoxicity assessed in a controlled cortical impact model. J. Neurochem. 61, 2015-2024. doi: 10. 1111/j.1471-4159.1993.tb07437.x

Pavlides, C., Watanabe, Y., and McEwen, B. S. (1993). Effects of glucocorticoids on hippocampal long-term potentiation. Hippocampus 3, 183-192. doi: 10. 1002/hipo.450030210

Rachmany, L., Tweedie, D., Rubovitch, V., Yu, Q. S., Li, Y., Wang, J. Y., et al. (2013). Cognitive impairments accompanying rodent mild traumatic brain injury involve p53-dependent neuronal cell death and are ameliorated by the tetrahydrobenzothiazole PFT-alpha. PLoS One 8:e79837. doi: 10.1371/journal. pone.0079837

Raghupathi, R., Graham, D. I., and McIntosh, T. K. (2000). Apoptosis after traumatic brain injury. J. Neurotrauma 17, 927-938. doi: 10.1089/neu.2000. 17.927

Raison, C. L., Capuron, L., and Miller, A. H. (2006). Cytokines sing the blues: inflammation and the pathogenesis of depression. Trends Immunol. 27, 24-31. doi: 10.1016/j.it.2005.11.006

Rao, V. L., Baskaya, M. K., Doğan, A., Rothstein, J. D., and Dempsey, R. J. (1998). Traumatic brain injury down-regulates glial glutamate transporter (GLT-1 and GLAST) proteins in rat brain. J. Neurochem. 70, 2020-2027. doi: 10.1046/j. 1471-4159.1998.70052020.x

Salim, S., Asghar, M., Taneja, M., Hovatta, I., Chugh, G., Vollert, C., et al. (2011). Potential contribution of oxidative stress and inflammation to anxiety and hypertension. Brain Res. 1404, 63-71. doi: 10.1016/j.brainres.2011. 06.024

Sapolsky, R. M. (1992). Cortisol concentrations and the social significance of rank instability among wild baboons. Psychoneuroendocrinology 17, 701-709. doi: 10.1016/0306-4530(92)90029-7

Sapolsky, R. M. (2005). The influence of social hierarchy on primate health. Science 308, 648-652. doi: 10.1126/science.1106477

Sapolsky, R. M. (2011). Physiological and pathophysiological implications of social stress in mammals. Compr. Physiol. 517-532. doi: 10.1002/cphy.cp070423

Sapolsky, R. M., Alberts, S. C., and Altmann, J. (1997). Hypercortisolism associated with social subordinance or social isolation among wild baboons. Arch. Gen. Psychiatry 54, 1137-1143. doi: 10.1001/archpsyc.1997.01830240 097014

Schmidt, M. L., Zhukareva, V., Newell, K. L., Lee, V. M., and Trojanowski, J. Q. (2001). Tau isoform profile and phosphorylation state in dementia pugilistica recapitulate alzheimer's disease. Acta Neuropathol. 101, 518-524.

Schuhr, B. (1987). Social structure and plasma corticosterone level in female albino mice. Physiol. Behav. 40, 689-693. doi: 10.1016/0031-9384(87)90269-1

Serra, M., Guaraldi, M., and Shea, T. B. (2010). Inhibitory neurons modulate spontaneous signaling in cultured cortical neurons: density-dependent regulation of excitatory neuronal signaling. Phys. Biol. 7:026009. doi: 10. $1088 / 1478-3975 / 7 / 2 / 026009$ 
Shea, T. B., and Rogers, E. (2014). Has prenatal folate supplementation established an at-risk population for age-related cognitive decline? J. Alzheimers Dis. 41, 667-669. doi: 10.3233/JAD-132675

Shea, T. B., Rogers, E., and Remington, R. (2014). "Nutritional approaches to mitigating cognitive decline and maintaining function in Alzheimer's disease: transgenic mouse models, combinatorial approaches and dietary supplementation with folate and S-adenosyl methionine," in Diet and Nutrition in Dementia and Cognitive Decline, eds C. R. Martin and V. R. Preedy (San Diego, CA: Elsevier Academic Press), 837-846.

Smith, D. H., Chen, X. H., Nonaka, M., Trojanowski, J. Q., Lee, V. Y., Saatman, K. E., et al. (1999). Accumulation of amyloid [beta] and tau and the formation of neurofilament inclusions following diffuse brain injury in the pig. J. Neuropathol. Exp. Neurol. 58, 982-992. doi: 10.1097/00005072-19990900000008

Taylor, C. A., Saint-Hilaire, M. H., Cupples, L. A., Thomas, C. A., Burchard, A. E., Feldman, R. G., et al. (1999). Environmental, medical and family history risk factors for parkinson's disease: a new england-based case control study. Am. J. Med. Genet. 88, 742-749. doi: 10.1002/(sici)10968628(19991215)88:6<742::aid-ajmg29>3.0.co;2-\#

Tyurin, V. A., Tyurina, Y. Y., Borisenko, G. G., Sokolova, T. V., Ritov, V. B., Quinn, P. J., et al. (2000). Oxidative stress following traumatic brain injury in rats: quantitation of biomarkers and detection of free radical intermediates. J. Neurochem. 75, 2178-2189. doi: 10.1046/j.1471-4159.2000.0752178.x

van der Ploeg, E. S., Eppingstall, B., Camp, C. J., Runci, S. J., Taffe, J., and O'Connor, D. W. (2013). A randomized crossover trial to study the effect of personalized, one-to-one interaction using montessori-based activities on agitation, affect and engagement in nursing home residents with dementia. Int. Psychogeriatr. 25, 565-575. doi: 10.1017/s1041610212002128

Xiong, Y., Gu, Q., Peterson, P. L., Muizelaar, J. P., and Lee, C. P. (1997). Mitochondrial dysfunction and calcium perturbation induced by traumatic brain injury. J. Neurotrauma 14, 23-34. doi: 10.1089/neu.1997.14.23
Yarnell, P. R., and Lynch, S. (1970). Retrograde memory immediately after concussion. Lancet 1, 863-864. doi: 10.1016/s0140-6736(70)9 1691-0

Yi, J. H., and Hazell, A. S. (2006). Excitotoxic mechanisms and the role of astrocytic glutamate transporters in traumatic brain injury. Neurochem. Int. 48, 394-403. doi: 10.1016/j.neuint.2005.12.001

Zemianek, J. M., Lee, S., Guaraldi, M., and Shea, T. B. (2012). Accelerated establishment of mature signaling patterns following stimulation of developing neuronal networks: "learning" versus "plasticity". Int. J. Dev. Neurosci. 30, 602-606. doi: 10.1016/j.ijdevneu.2012.08.001

Zemianek, J. M., Lee, S., Guaraldi, M., and Shea, T. B. (2013a). Critical role for inhibitory neurons in modulation of synaptic signaling in ex vivo neuronal networks. Int. J. Dev. Neurosci. 31, 308-310. doi: 10.1016/j.ijdevneu.2013. 03.011

Zemianek, J. M., Shultz, A. M., Lee, S., Guaraldi, M., Yanco, H. A., and Shea, T. B. (2013b). Transient epileptiform signaling during neuronal network development: regulation by external stimulation and bimodal GABAergic activity. Int. J. Dev. Neurosci. 31, 131-137. doi: 10.1016/j.ijdevneu.2012. 11.003

Conflict of Interest Statement: The authors declare that the research was conducted in the absence of any commercial or financial relationships that could be construed as a potential conflict of interest.

Copyright (c) 2015 Doulames, Vilcans, Lee and Shea. This is an open-access article distributed under the terms of the Creative Commons Attribution License (CC BY). The use, distribution and reproduction in other forums is permitted, provided the original author(s) or licensor are credited and that the original publication in this journal is cited, in accordance with accepted academic practice. No use, distribution or reproduction is permitted which does not comply with these terms. 